\title{
Impaired fasting glycaemia vs impaired glucose tolerance: similar impairment of pancreatic alpha and beta cell function but differential roles of incretin hormones and insulin action
}

\author{
K. Færch • A. Vaag • J. J. Holst • C. Glümer • \\ O. Pedersen $\cdot$ K. Borch-Johnsen
}

Received: 15 November 2007 / Accepted: 21 January 2008/Published online: 4 March 2008

(C) Springer-Verlag 2008

\begin{abstract}
Aims/hypothesis The impact of strategies for prevention of type 2 diabetes in isolated impaired fasting glycaemia (i-IFG) vs isolated impaired glucose tolerance (i-IGT) may differ depending on the underlying pathophysiology. We examined insulin secretion during OGTTs and IVGTTs, hepatic and peripheral insulin action, and glucagon and incretin hormone secretion in individuals with i-IFG $(n=18)$, i-IGT $(n=28)$ and normal glucose tolerance (NGT, $n=20)$. Methods Glucose tolerance status was confirmed by a repeated OGTT, during which circulating insulin, glucagon, glucose-dependent insulinotrophic polypeptide (GIP) and glucagon-like peptide-1 (GLP-1) levels were measured. A euglycaemic-hyperinsulinaemic clamp with $\left[3-{ }^{3} \mathrm{H}\right]$ glucose preceded by an IVGTT was performed.

Results Absolute first-phase insulin secretion during IVGTT was decreased in i-IFG $(p=0.026)$, but not in
\end{abstract}

K. Færch $(\bowtie) \cdot$ A. Vaag $\cdot$ O. Pedersen $\cdot$ K. Borch-Johnsen Steno Diabetes Center,

Niels Steensens Vej 2,

DK-2820 Gentofte, Denmark

e-mail: krif@steno.dk

J. J. Holst

Department of Biomedical Sciences, The Panum Institute,

University of Copenhagen,

Copenhagen, Denmark

C. Glümer

Research Centre for Prevention and Health,

Glostrup, Capital Region of Denmark, Denmark

O. Pedersen $\cdot$ K. Borch-Johnsen

University of Aarhus,

Aarhus, Denmark
i-IGT $(p=0.892)$ compared with NGT. Hepatic insulin sensitivity was normal in i-IFG and i-IGT individuals $(p \geq$ 0.179). Individuals with $\mathrm{i}$-IGT had peripheral insulin resistance ( $p=0.003$ vs NGT), and consequently the disposition index (DI; insulin secretion $\times$ insulin sensitivity) during IVGTT (DI $\left.\mathrm{IVGTT}_{\text {) }}\right)$ was reduced in both i-IFG and iIGT $(p<0.005$ vs NGT). In contrast, the DI during OGTT $\left(\right.$ DI $\left._{\text {OGTT }}\right)$ was decreased only in i-IGT $(p<0.001)$, but not in i-IFG $(p=0.143)$ compared with NGT. Decreased levels of GIP in i-IGT ( $p=0.045$ vs NGT) vs increased levels of GLP-1 in i-IFG ( $p=0.013$ vs NGT) during the OGTT may partially explain these discrepancies. Basal and post-load glucagon levels were significantly increased in both i-IFG and i-IGT individuals ( $p \leq 0.001$ vs NGT).

Conclusions/interpretation We propose that differentiated preventive initiatives in prediabetic individuals should be tested, targeting the specific underlying metabolic defects.

Keywords Disposition index · Glucagon - Impaired fasting glycaemia - Impaired glucose tolerance · Incretin hormones . Insulin secretion · Insulin sensitivity · Pathophysiology · Prediabetes
Abbreviations
DI disposition index
EGP endogenous glucose production
FFM
FPG
GIP fat-free mass
GLP-1 fasting plasma glucose
i-IFG glucose-dependent insulinotrophic polypeptide
i-IGT
NGT normal glucose tolerance glucagon-like peptide-1
isolated impaired fasting glycaemia
2 h PG 2 h plasma glucose 


\section{Introduction}

To gain a more profound insight into the pathogenesis of type 2 diabetes, the initial defects responsible for fasting vs post-load glucose dysregulation need to be elucidated in individuals with isolated impaired fasting glycaemia (i-IFG) and isolated impaired glucose tolerance (i-IGT). Those with combined IFG/IGT most probably represent a mixed group with more severe defects in several organs [1]. In a recent review [2] it was concluded that hepatic insulin resistance is a dominant feature in i-IFG and peripheral insulin resistance is a characteristic of those with i-IGT, while both groups have impaired absolute insulin secretion. However, the majority of previous studies based their estimates of insulin secretion and insulin sensitivity on fasting and/or post-load samples from an OGTT [3-10]. While estimates of insulin secretion and action based on fasting plasma insulin and glucose levels are known to be indirect and rather simple, measurements based on oral (compared with i.v.) glucose administration may to some extent be influenced by the secretion and action of gut incretin hormones, causing less accurate estimates of pancreatic beta cell function. Furthermore, only a single study in prediabetic individuals [11] previously reported measurements of insulin secretion as seen in relation to insulin action using gold-standard techniques, providing a true measure of pancreatic beta cell function.

In the present detailed study, we aimed at examining hepatic and peripheral insulin sensitivity as well as the secretion of insulin, glucagon and incretin hormones in a population-based study of incident cases of i-IFG vs i-IGT by using both oral and i.v. methods.

\section{Methods}

All participants were recruited from the Inter99 study [12], which is a 5 year population-based non-pharmacological intervention study with the aim of reducing incidence of ischaemic heart disease and type 2 diabetes. C. Glümer and K. Borch-Johnsen are members of the Steering Committee for Inter99, with K. Borch-Johnsen being principal investigator for the areas relating to diabetes. The randomisation and intervention strategies used in the Inter99 study are described elsewhere [12].

Classification of glucose tolerance status based on repeated OGTT At baseline (1999-2001) and at 5 year follow-up (2004-2006), all participants had a standard 75 g OGTT with glucose and insulin measured at time 0 and $120 \mathrm{~min}$. A total of 4,735 individuals had normal glucose tolerance (NGT) at baseline, and at the 5 year examination 2,842 of these had NGT, 83 had i-IFG and 192 had i-IGT (Fig. 1). A random sample of these individuals was invited for a repeated OGTT (NGT: $n=127$, i-IFG: $n=50$, i-IGT: $n=$ 104). Of these, $120(42.7 \%)$ gave a written informed consent to participate, and the repeated OGTT was performed within $159 \pm 78($ mean \pm SD) days after the last OGTT. For the repeated OGTT, samples were drawn at $-10,0,10,20,30,45,60,75,90,120,150$ and $180 \mathrm{~min}$ for assessment of glucose, insulin, C-peptide, glucagon, glucose-dependent insulinotrophic polypeptide (GIP) and glucagon-like peptide-1 (GLP-1).

If the repeated OGTT of these 120 individuals confirmed i-IFG, i-IGT or NGT, the participants were invited to continue their participation in the study. The confirmation of glucose tolerance status was based on the average values of fasting plasma glucose (FPG) and $2 \mathrm{~h}$ plasma glucose (2 h PG) concentrations from the two repeated OGTTs: (1) NGT was defined as FPG $<6.1 \mathrm{mmol} / 1$ and $2 \mathrm{~h}$ PG $<7.8 \mathrm{mmol} / \mathrm{l}$; (2) $\mathrm{i}$-IFG was defined as $6.1 \mathrm{mmol} / \mathrm{l} \leq \mathrm{FPG}<$ $7.0 \mathrm{mmol} / \mathrm{l}$ and $2 \mathrm{~h} \mathrm{PG}<7.8 \mathrm{mmol} / \mathrm{l}$; and (3) $\mathrm{i}-\mathrm{IGT}$ was defined as FPG $<6.1$ and $7.8 \mathrm{mmol} / 1 \leq 2 \mathrm{~h} \mathrm{PG}<11.1 \mathrm{mmol} / \mathrm{l}$ [13]. Of the 120 individuals having a repeated OGTT, 72 had their glucose tolerance status confirmed and 66 of these agreed to participate further in the study.

IVGTT and the euglycaemic-hyperinsulinaemic clamp Within $17 \pm 14$ (mean $\pm \mathrm{SD}$ ) days after the repeated OGTT, the 66 participants underwent an examination of insulin secretion and action after an overnight fast. Basal samples for glucose, NEFA, $\mathrm{HbA}_{1 \mathrm{c}}$, insulin and C-peptide determina-

\begin{tabular}{|l|l}
\hline BASELINE: \\
OGTT (1999-2001) \\
NGT: $n=4,735$
\end{tabular}$\quad \rightarrow$\begin{tabular}{lll|}
$\begin{array}{l}\text { 5 YEAR FOLLOW-UP: } \\
\text { OGTT (2004-2006) }\end{array}$ & $\rightarrow$ Repeated OGTT $\rightarrow$ IVGTT and clamp \\
& NGT: $n=25$ & NGT: $n=20$ \\
NGT: $n=2,842$ & i-IFG: $n=30$ & i-IFG: $n=18$ \\
i-IFG: $n=83$ & i-IGT: $n=55$ & i-IGT: $n=28$ \\
i-IGT: $n=192$ &
\end{tabular}

Fig. 1 Flow-chart of the study design. At baseline (1999-2001), 4,735 individuals had NGT based on an OGTT in the Inter99 study. After 5 years (2004-2006), another OGTT was performed and a random sample of 281 individuals with NGT, i-IFG, and i-IGT was invited to participate further in the study. A total of 120 individuals underwent a repeated OGTT, and glucose tolerance status was confirmed in 72 individuals. Of these, 66 continued their participation into the last part of the study, which was a euglycaemic-hyperinsulinaemic clamp preceded by an IVGTT 
tion were obtained. Thereafter, the study started out with a basal period of $2 \mathrm{~h}$ initiated by an adjusted priming tracer dose of $\left[3-{ }^{3} \mathrm{H}\right]$ glucose [14] followed by a constant i.v. tracer infusion $(0.22 \mathrm{MBq} / \mathrm{h})$, which was continued for the entire study period of $4.5 \mathrm{~h}$. After the $2 \mathrm{~h}$ basal period, a $30 \mathrm{~min}$ IVGTT was performed to characterise the firstphase insulin response. Thereafter, a $2 \mathrm{~h}$ euglycaemichyperinsulinaemic clamp was initiated for estimation of peripheral insulin sensitivity $[15,16]$.

For initiating the IVGTT, a $1 \mathrm{~min}$ i.v. glucose bolus (20\% [wt/vol.], $0.3 \mathrm{~g} / \mathrm{kg}$ body weight) was infused at time $0 \mathrm{~min}$. Blood samples were drawn for whole blood glucose concentration as well as serum insulin and C-peptide determination at $-2,0,2,4,6,8,10$ and $30 \mathrm{~min}$.

During the clamp, a $20 \%$ glucose solution was infused at a variable rate, adjusted every $5 \mathrm{~min}$ in order to maintain a predetermined blood glucose concentration of $5 \mathrm{mmol} / \mathrm{l}$ [15]. ${ }^{3} \mathrm{H}$-labelled glucose $\left(3,670 \mathrm{~Bq} / \mathrm{ml}\left[3{ }^{3} \mathrm{H}\right]\right.$ glucose $)$ was added to the infused glucose solution to obtain constant specific activity during insulin infusion. Indirect calorimetry was performed during the last $40 \mathrm{~min}$ of the near-steady-state basal and clamp period.

Body composition Body weight was measured to the nearest $0.1 \mathrm{~kg}$ using a standard electronic weighing machine (BWB620A; Tanita, Chicago, IL, USA) with the participant wearing light clothes. Height was measured to the nearest $0.5 \mathrm{~cm}$ with the participant not wearing shoes. Total body fat and fat-free mass (FFM) were determined by a bioimpedance analyser (Biodynamics, Seattle, WA, USA).

Blood samples Blood samples for measurement of venous plasma glucose during the OGTT and IVGTT as well as $\left[3-{ }^{3} \mathrm{H}\right]$ glucose during the clamp were taken in a tube containing sodium fluoride and put on ice immediately. Plasma glucose was analysed using the hexokinase/G6P-DH technique (Roche Diagnostics, Mannheim, Germany), and $\left[3-{ }^{3} \mathrm{H}\right]$ glucose activity was determined from evaporated plasma samples [14]. Plasma ${ }^{3} \mathrm{H}_{2} \mathrm{O}$ was determined from the activity in the plasma sample minus the activity in the same plasma sample after evaporation. During the clamp, whole blood glucose was measured on a One Touch Profile glucose meter (Lifescan, Milpitas, CA, USA). Samples for measurement of serum insulin and C-peptide were analysed with a fluoro-immunoassay technique (AutoDELFIA; Perkin Elmer-Wallac, Turku, Finland). Plasma NEFA were quantified using an enzymatic colorimetric method (Wako Chemicals, Neuss, Germany). Blood samples for measurement of glucagon, GIP and GLP-1 were taken in tubes containing EDTA and were put on ice immediately. For the GIP RIA [17] we used the C-terminally directed antiserum $\mathrm{R}$ 65. The plasma concentrations of GLP-1 were measured [18] against standards of synthetic GLP-1 7-36-amide using antiserum code no. 89390, which is specific for the amidated C-terminus of GLP-1, and therefore mainly reacts with GLP-1 of intestinal origin (all antisera were supplied by the Department of Biomedical Sciences, University of Copenhagen, Copenhagen, Denmark). Both of these assays measure the sum of the intact, active hormones and the metabolites generated by dipeptidylpeptidase-4 (GIP3-42 and GLP-1 9-36-amide). The results therefore reflect the secretion of the two hormones. The glucagon RIA was directed against the $\mathrm{C}$-terminus of the glucagon molecule (antibody code no. 4305) and therefore mainly measures glucagon of pancreatic origin [19]. For all three assays, which were carried out after $70 \%$ ethanol extraction of plasma to remove unspecific interference, sensitivity was $<1 \mathrm{pmol} / 1$ and inter- and intra-assay CV values were $<0.06$ and $<0.15$, respectively.

Calculations Steele's non-steady-state equation [20], which takes minor fluctuations in blood glucose concentration into account was used to estimate endogenous glucose production (EGP) during the two near-steady-state periods (basal and insulin-stimulated). EGP was calculated as the ratio between the tracer infusion rate $(\mathrm{Bq} / \mathrm{min})$ and the specific activity $(\mathrm{Bq} / \mathrm{mg})$. During insulin-stimulation, the glucose infusion rate was subtracted from the rate of appearance of $\left[{ }^{3} \mathrm{H}\right]$ glucose in the calculation of EGP. A total glucose pool of $200 \mathrm{ml} / \mathrm{kg}$ body mass and a pool fraction of 0.65 were used in the calculations [20]. Tracer data for four individuals were excluded from the analysis because of inaccurate procedures. First-phase insulin secretion during the IVGTT was calculated as the incremental AUC for insulin during the first $10 \mathrm{~min}$ of the IVGTT using the trapezoidal rule. An estimate of firstphase insulin secretion was also calculated from the OGTT using the insulinogenic index $(\Delta \mathrm{I} 30 / \Delta \mathrm{G} 30)$ [21]. Peripheral insulin sensitivity was calculated from the clamp as the insulin-dependent glucose disposal rate ( $M$ value) divided by the mean serum insulin concentration during the last $30 \mathrm{~min}$ steady-state period of the clamp (mean \pm SD: $407 \pm 22 \mathrm{pmol} / 1$ (NGT); $389 \pm 23 \mathrm{pmol} / \mathrm{l}$ (i-IFG); $456 \pm 19 \mathrm{pmol} / \mathrm{l}$ (i-IGT)). Hepatic insulin resistance was estimated as basal EGP multiplied by fasting serum insulin concentration [22]. Beta cell function (disposition index [DI]) during IVGTT (DI IVGTT $_{\text {) and }}$ OGTT ( DI $_{\text {OGTT }}$ ) was calculated as peripheral insulin sensitivity multiplied by first-phase insulin secretion or $\Delta \mathrm{I} 30 / \Delta \mathrm{G} 30$, respectively. The AUCs for GIP, GLP-1 and glucagon during the $3 \mathrm{~h}$ OGTT were calculated using the trapezoidal rule.

Statistical analysis Individuals with i-IFG, i-IGT and NGT were compared with each other using one-way ANOVA. Non-normally distributed variables were log-transformed. The results are reported as means $\pm \mathrm{SE}$ or geometric means \pm SE. SAS version 9.1 (SAS Institute, Cary, USA) was used for statistical analysis. 


\section{Results}

Clinical characteristics of the study participants are shown in Table 1. Sex was not equally distributed in the three glucose tolerance groups because of a lower number of women with i-IFG.

BMI were similar in i-IFG and i-IGT individuals, but significantly higher than in NGT individuals. FFM was higher in individuals with i-IFG compared with i-IGT, but this was because of the higher proportion of men in the i-IFG group. When only men were analysed no significant differences were observed in FFM between the groups ( $p \geq$ 0.387 for all comparisons).

Plasma glucose response During the OGTT, because of the inclusion criteria, individuals with $\mathrm{i}-\mathrm{IFG}$ had elevated FPG, while those with i-IGT had elevated 2 h PG compared with NGT (Table 2; Fig. 2a). During the IVGTT, plasma glucose concentration reached its maximum after 2 min with no significant differences between the groups ( $p \geq 0.147$ for all comparisons; Fig. 3a).

Insulin resistance, clamp A reduction in peripheral insulin sensitivity was observed in individuals with i-IGT compared with NGT and i-IFG, but peripheral insulin sensitivity was normal in individuals with i-IFG. Hepatic insulin resistance did not differ statistically significantly between the groups ( $p \geq 0.179$ for all comparisons; Table 2).

Insulin secretion/beta cell function During the OGTT, fasting serum insulin concentration did not differ between the groups, but it tended to be higher in the i-IGT group $(p=0.066)$. The $2 \mathrm{~h}$ insulin concentration was significantly higher in $\mathrm{i}-\mathrm{IGT}$ individuals compared with the other groups ( $p \leq 0.002$; Table 2$)$. C-peptide and insulin excursions were similar in NGT and i-IFG individuals, but in the i-IGT group C-peptide and insulin peaked and levelled off later than for NGT and i-IFG (Fig. 2b,c). The insulinogenic index estimated from the OGTT did not differ between the groups, but after adjusting for peripheral insulin resistance, DI $_{\text {OGTT }}$ was significantly diminished in the i-IGT group compared with the NGT and i-IFG group ( $p \leq 0.044)$, whereas no significant difference was observed between i-IFG and NGT ( $p=0.143$; Table 2). During the IVGTT, serum insulin concentrations peaked after $4 \mathrm{~min}$ for all groups, but the $4 \mathrm{~min}$ insulin concentration was on average lower in the $\mathrm{i}-\mathrm{IFG}$ group compared with the other groups $(p \leq 0.050$; Fig. 3b). First-phase insulin secretion was significantly lower in individuals with i-IFG compared with the groups of NGT and i-IGT ( $p=0.026$; Table 2). After adjustment for peripheral insulin sensitivity, DI IVGTT $_{\text {IVT }}$ was significantly lower in both i-IFG and i-IGT compared with NGT individuals ( $p \leq 0.005$; Table 2).

Incretin hormones, OGTT The basal level of GIP did not differ between the groups ( $p \geq 0.130$ for all comparisons; Fig. 2e). The $3 \mathrm{~h}$ AUC for GIP was significantly lower in the group of i-IGT compared with those with NGT $(p=0.045)$, but normal in the $\mathrm{i}-\mathrm{IFG}$ group $(p=0.592$; Table 2). Fasting GLP-1 did not differ between NGT, i-IFG and i-IGT individuals ( $p \geq 0.242$ for all comparisons, Fig. 2f), but those with i-IFG had a significantly higher $3 \mathrm{~h}$ AUC for GLP-1 than those with NGT ( $p=0.013$; Table 2).

Glucagon, OGTT Individuals with i-IFG and i-IGT had a significantly higher fasting, 1 and $2 \mathrm{~h}$ glucagon concentration $(p \leq 0.013)$ as well as a higher $3 \mathrm{~h}$ AUC compared with those with NGT $(p<0.001$; Table 2, Fig. 2d).

\section{Discussion}

This study emphasises that defects in fasting and post-load (postprandial) glucose metabolism are caused by different mechanisms. In the absolute sense, individuals with i-IFG have reduced insulin secretion in response to i.v. but not oral glucose administration, and they have normal insulin action. In contrast, individuals with i-IGT have normal

Table 1 Clinical characteristics of individuals with NGT, i-IFG and i-IGT

\begin{tabular}{|c|c|c|c|c|c|c|}
\hline & \multirow[t]{2}{*}{ NGT $(n=20)$} & \multirow[t]{2}{*}{ i-IFG $(n=18)$} & \multirow[t]{2}{*}{ i-IGT $(n=28)$} & \multicolumn{3}{|l|}{$p$ value } \\
\hline & & & & i-IFG vs NGT & i-IGT vs NGT & i-IGT vs i-IFG \\
\hline $\operatorname{Sex}(M / F)$ & $11 / 9$ & $16 / 2$ & $16 / 12$ & & & \\
\hline Age (years) & $49.8 \pm 0.9$ & $53.9 \pm 2.03$ & $54 \pm 1.63$ & 0.139 & 0.092 & 0.966 \\
\hline BMI $\left(\mathrm{kg} / \mathrm{m}^{2}\right)$ & $25.6 \pm 0.76$ & $27.8 \pm 0.80$ & $27.9 \pm 0.64$ & 0.040 & 0.016 & 0.905 \\
\hline FFM $(\%)$ & $73.4 \pm 1.4$ & $75.7 \pm 1.5$ & $71.4 \pm 1.2$ & 0.251 & 0.277 & 0.022 \\
\hline Systolic BP (mmHg) & $126.7 \pm 4.2$ & $136.9 \pm 4.5$ & $136.3 \pm 4.0$ & 0.097 & 0.097 & 0.917 \\
\hline $\mathrm{HbA}_{1 \mathrm{c}}(\%)$ & $5.35 \pm 0.08$ & $5.54 \pm 0.09$ & $5.41 \pm 0.07$ & 0.093 & 0.513 & 0.247 \\
\hline
\end{tabular}

Data are means \pm SE

M, male; F, female 
Table 2 Metabolic characteristics of individuals with NGT, i-IFG and i-IGT during OGTTs, IVGTTs and a euglycaemic-hyperinsulinaemic clamp (basal and insulin-stimulated period)

$\begin{array}{lll}\text { NGT } & \text { i-IFG } & \text { i-IGT } \\ (n=20) & (n=18) & (n=28)\end{array}$

$p$ value

i-IFG vs NGT i-IGT vs NGT i-IGT vs

i-IFG

\begin{tabular}{|c|c|c|c|c|c|c|}
\hline \multicolumn{7}{|l|}{ OGTT } \\
\hline FPG $(\mathrm{mmol} / \mathrm{l})$ & $5.42 \pm 0.08$ & $6.20 \pm 0.09$ & $5.65 \pm 0.07$ & $<0.001$ & 0.029 & $<0.001$ \\
\hline 2 h PG $(\mathrm{mmol} / \mathrm{l})$ & $6.50 \pm 0.25$ & $5.95 \pm 0.27$ & $8.69 \pm 0.21$ & 0.139 & $<0.001$ & $<0.001$ \\
\hline Fasting serum insulin $(\mathrm{pmol} / 1)^{\mathrm{a}}$ & $33.29 \pm 4.22$ & $38.27 \pm 5.12$ & $45.16 \pm 4.84$ & 0.449 & 0.066 & 0.334 \\
\hline $2 \mathrm{~h}$ serum insulin $(\mathrm{pmol} / \mathrm{l})^{\mathrm{a}}$ & $201.2 \pm 35.1$ & $145.6 \pm 26.8$ & $404.3 \pm 59.5$ & 0.202 & 0.002 & $<0.001$ \\
\hline 3 h AUC GIP (nmol/l) & $10.02 \pm 0.86$ & $9.35 \pm 0.91$ & $7.75 \pm 0.74$ & 0.592 & 0.045 & 0.171 \\
\hline 3 h AUC GLP-1 (nmol/1) & $4.31 \pm 0.47$ & $6.02 \pm 0.50$ & $5.33 \pm 0.41$ & 0.013 & 0.102 & 0.290 \\
\hline 3 h AUC glucagon (nmol/1) & $1.10 \pm 0.12$ & $1.85 \pm 0.13$ & $1.74 \pm 0.10$ & $<0.001$ & $<0.001$ & 0.504 \\
\hline Insulinogenic index $([\mathrm{pmol} / \mathrm{mmol}])^{\mathrm{a}}$ & $70.7 \pm 10.1$ & $65.8 \pm 10.2$ & $61.7 \pm 7.4$ & 0.728 & 0.465 & 0.746 \\
\hline $\begin{array}{l}\mathrm{DI}_{\mathrm{OGTT}},\left(\times 10^{-3} \mathrm{mmol} \mathrm{kg}^{-1} \mathrm{FFM} \mathrm{min}{ }^{-1}\right. \\
\left.[\mathrm{pmol} / 1]^{-1}\right)(\mathrm{pmol} / \mathrm{mmol})^{\mathrm{a}}\end{array}$ & $8.62 \pm 1.06$ & $6.58 \pm 0.90$ & $4.65 \pm 0.49$ & 0.143 & $<0.001$ & 0.044 \\
\hline \multicolumn{7}{|l|}{ IVGTT } \\
\hline First-phase insulin secretion $(\mathrm{nmol} / \mathrm{l})^{\mathrm{a}}$ & $1.71 \pm 0.26$ & $1.04 \pm 0.17$ & $1.66 \pm 0.22$ & 0.026 & 0.892 & 0.026 \\
\hline $\begin{array}{l}\mathrm{DI}_{\text {IVGTT }},\left(\times 10^{-3} \mathrm{mmol} \mathrm{kg}^{-1} \mathrm{FFM} \mathrm{m^{-1 }}\right. \\
\left.[\mathrm{pmol} / 1]^{-1}\right)(\mathrm{nmol} / 1)^{\mathrm{a}}\end{array}$ & $207.9 \pm 28.5$ & $103.7 \pm 15.4$ & $123.3 \pm 15.1$ & $<0.001$ & 0.005 & 0.370 \\
\hline \multicolumn{7}{|l|}{ Clamp } \\
\hline \multicolumn{7}{|l|}{ Basal period } \\
\hline Specific activity of tracer $(\mathrm{Bq} / \mathrm{mg})$ & $6.46 \pm 0.26$ & $6.17 \pm 0.27$ & $6.59 \pm 0.22$ & 0.434 & 0.700 & 0.224 \\
\hline Plasma NEFA $(\mu \mathrm{mol} / 1)^{\mathrm{a}}$ & $271.6 \pm 28.6$ & $278.1 \pm 30.9$ & $342.9 \pm 30.6$ & 0.877 & 0.091 & 0.142 \\
\hline $\operatorname{EGP}\left(\times 10^{-3} \mathrm{mmol} \mathrm{min}^{-1} \mathrm{~kg} \mathrm{FFM}^{-1}\right)$ & $15.4 \pm 0.9$ & $14.1 \pm 1.0$ & $13.5 \pm 0.8$ & 0.334 & 0.119 & 0.640 \\
\hline $\begin{array}{l}\text { Hepatic insulin resistance }\left(\mathrm{mmol} \mathrm{min} \mathrm{m}^{-1} \mathrm{~kg}^{-1}\right. \\
\left.\text { FFM }[\mathrm{pmol} / \mathrm{l}]^{-1}\right)^{\mathrm{a}}\end{array}$ & $0.54 \pm 0.09$ & $0.61 \pm 0.10$ & $0.70 \pm 0.08$ & 0.570 & 0.179 & 0.499 \\
\hline \multicolumn{7}{|l|}{ Insulin-stimulated period } \\
\hline$M$ value $\left(\times 10^{-3} \mathrm{mmol} \mathrm{min}^{-1} \mathrm{~kg}^{-1} \mathrm{FFM}\right)$ & $49.3 \pm 3.10$ & $45.1 \pm 4.0$ & $37.1 \pm 3.1$ & 0.434 & 0.012 & 0.117 \\
\hline $\begin{array}{l}\text { Peripheral insulin sensitivity }\left(\times 10^{-6} \mathrm{mmol} \mathrm{kg}^{-1}\right. \\
\left.\text { FFM } \min ^{-1}[\mathrm{pmol} / 1]^{-1}\right)\end{array}$ & $130.2 \pm 11.7$ & $122.2 \pm 12.7$ & $84.9 \pm 10.1$ & 0.643 & 0.003 & 0.021 \\
\hline Specific activity of tracer $(\mathrm{Bq} / \mathrm{mg})$ & $6.70 \pm 0.29$ & $6.73 \pm 0.29$ & $6.66 \pm 0.23$ & 0.943 & 0.920 & 0.858 \\
\hline Plasma NEFA $(\mu \mathrm{mol} / \mathrm{l})^{\mathrm{a}}$ & $19.4 \pm 2.1$ & $29.2 \pm 3.2$ & $29.5 \pm 2.6$ & 0.008 & 0.003 & 0.937 \\
\hline EGP $\left(\times 10^{-3} \mathrm{mmol} \mathrm{min}^{-1} \mathrm{~kg}^{-1} \mathrm{FFM}\right)$ & $11.7 \pm 3.7$ & $8.8 \pm 3.7$ & $10.0 \pm 2.9$ & 0.569 & 0.718 & 0.787 \\
\hline
\end{tabular}

Data are means $\pm \mathrm{SE}$

${ }^{\mathrm{a}}$ Geometric means $\pm \mathrm{SE}$

absolute oral and i.v. glucose-stimulated insulin secretion, but they exhibit substantial peripheral insulin resistance. Nevertheless, after correction for the ambient individual degree of insulin resistance, individuals with i-IFG and i-IGT have a similar degree of beta cell dysfunction in response to i.v. glucose administration. During oral glucose ingestion, individuals with i-IGT exhibit impaired beta cell function, whereas the OGTT-derived beta cell function for those with $\mathrm{i}$-IFG is near normal. The observed impaired secretion of GIP in individuals with i-IGT vs an elevated GLP-1 response in those with i-IFG may partially explain this discrepancy. Individuals with i-IFG and i-IGT exhibit similar degree of elevated plasma glucagon levels in the face of normal EGP in relation to the basal level of insulin (i.e. normal hepatic insulin sensitivity).

Insulin secretion Most previous studies in i-IFG vs i-IGT individuals have used either only oral or only i.v. tests, and in none of these studies were simultaneous measurements of insulin action, glucagon and gut incretin hormone secretion performed. The present study highlights the importance of discriminating between insulin secretion estimates derived from either oral or i.v. glucose challenge tests, the relevance of measuring gut incretin hormones when evaluating insulin secretion rates, and finally the impact of adjusting for in vivo insulin action.

The divergent results between estimates of beta cell function during oral vs i.v. glucose administration in i-IFG vs $\mathrm{i}$-IGT individuals $[1,3-10,23-25]$ questions the reliability of, in particular, oral glucose challenges as relevant measures of beta cell function. After oral glucose ingestion, insulin secretion is highly dependent on the incretin hormone secretion and action. Since we have shown that the levels of GIP and GLP-1 may differ markedly between the different prediabetic phenotypes, 
a

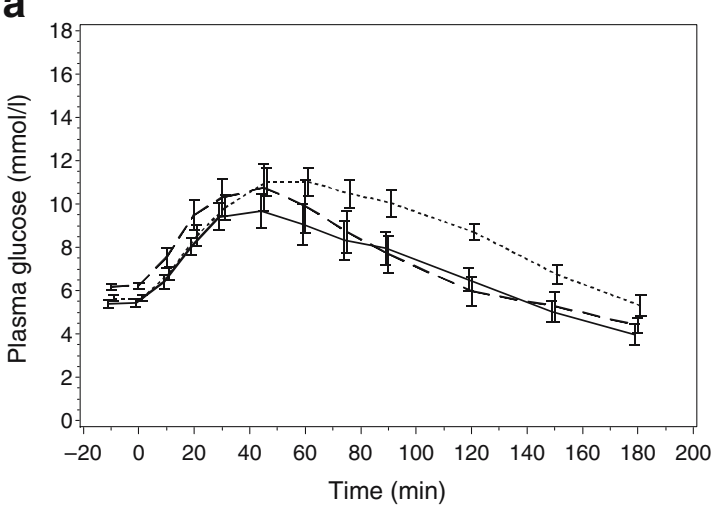

C

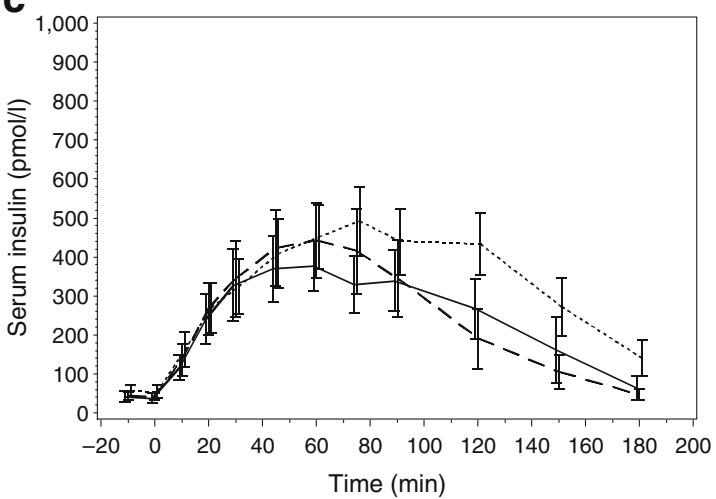

e

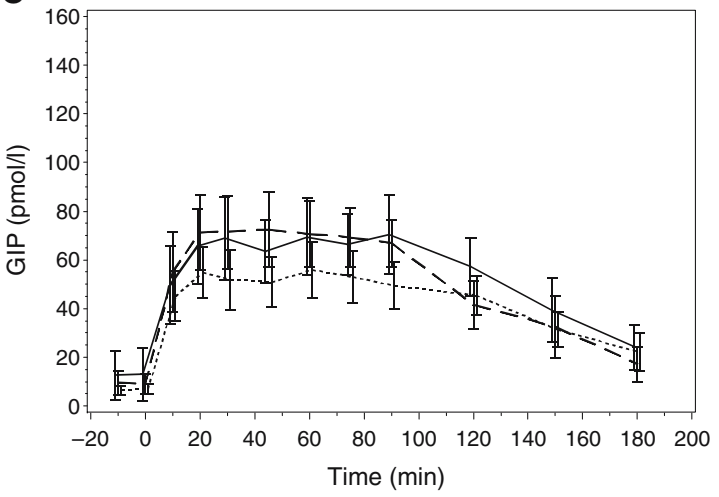

Fig. 2 Plasma glucose (a), serum C-peptide (b), serum insulin (c), plasma glucagon (d), plasma GIP (e) and plasma GLP-1 (f) in individuals with NGT (solid lines), i-IFG (dashed lines) and i-IGT

the observed differences in beta cell function in studies using only OGTTs $[3,4,8-10]$ may be caused by differential incretin hormone secretion or action, and should therefore be interpreted with caution.

Previous reports on defective insulin secretion in i-IFG vs i-IGT individuals [1, 3-10, 23-25] may also to some extent be explained by misclassification because of only a single OGTT and/or differences in the duration of impaired glucose regulation in the studied individuals. In none of the previous studies was the onset of impaired glucose regulation known, and therefore the results of these studies may reflect pathophysiological mechanisms at a stage later in the b

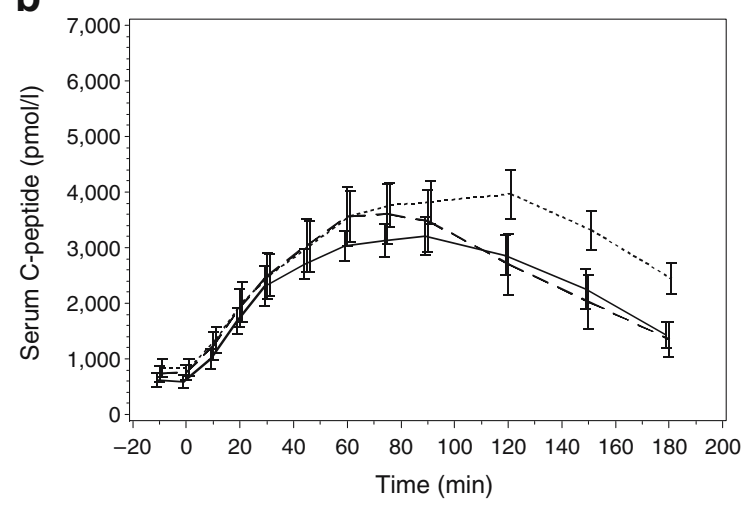

d

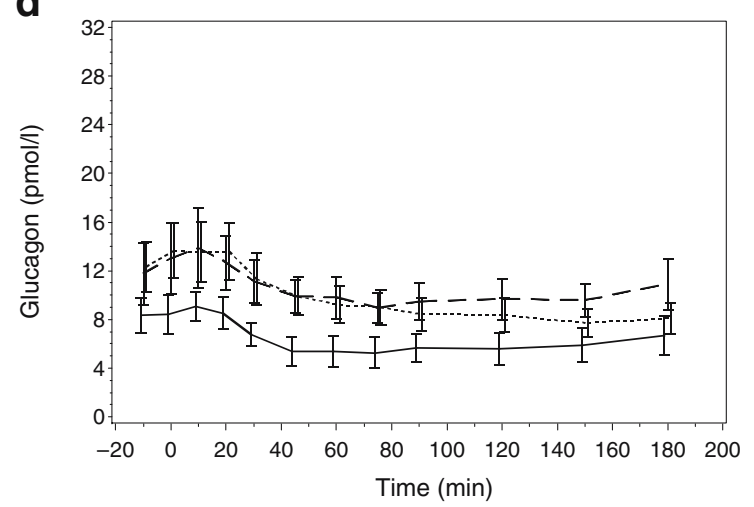

f

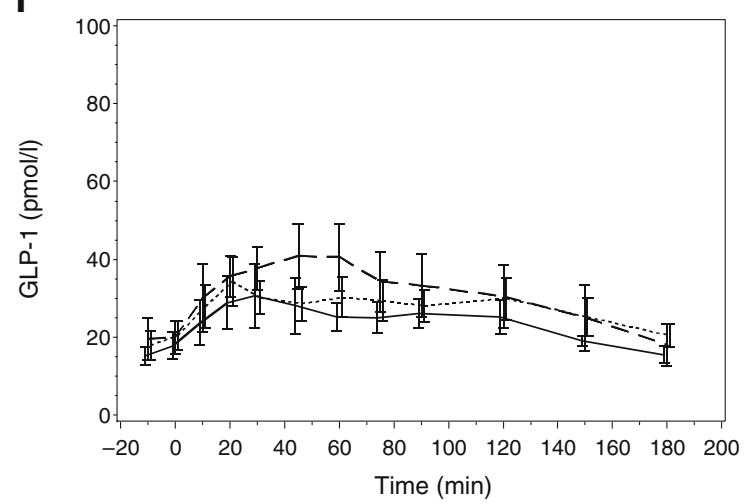

(dotted lines) during the OGTT. Values are means with SE shown by vertical lines for $n=66$ individuals

development towards overt type 2 diabetes than our results, which are based on participants identified 5 years after having NGT. Moreover, most studies have based their classification of i-IFG and i-IGT on a single OGTT, which increases the likelihood of misclassification. Our classification of NGT at baseline was also only based on a single OGTT. However, since more than $90 \%$ of individuals with NGT are likely to be reclassified as NGT at a repeated OGTT [26], we believe that misclassification is not an important concern in this study.

When estimating insulin secretion, it is also important to correct for insulin resistance (i.e. calculating the DI) to obtain a true estimate of beta cell dysfunction. Despite large 
a

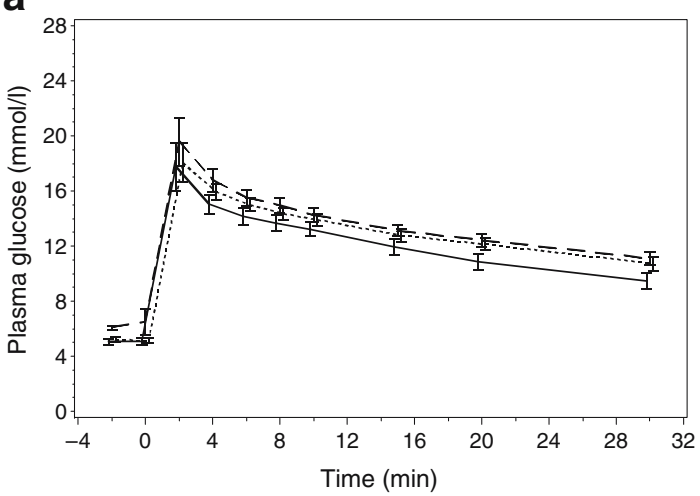

b

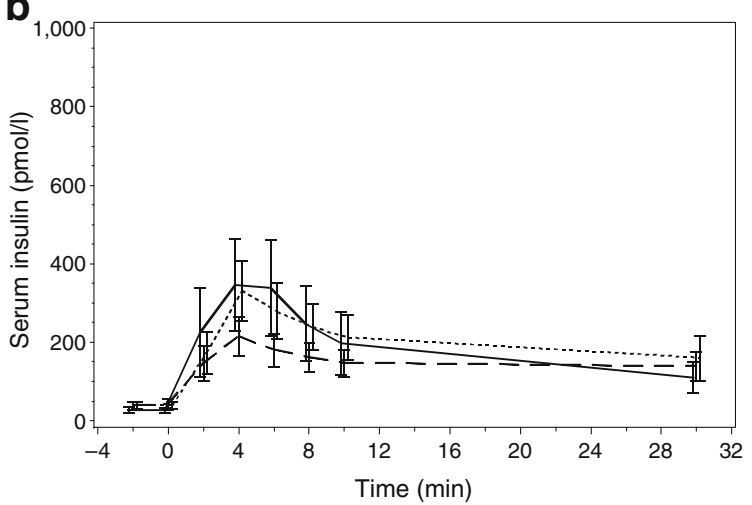

Fig. 3 Plasma glucose (a) and serum insulin (b) concentrations in individuals with NGT (solid lines), i-IFG (dashed lines) and i-IGT (dotted lines) during the IVGTT. Values are means with SE shown by vertical lines for $n=66$ individuals

differences in first-phase insulin secretion, individuals with i-IFG and i-IGT had the same reduction in DI, which has also been previously reported by others [11].

Incretin hormones Incretin hormone secretion in individuals with i-IFG and i-IGT has not been examined in detail previously. However, impaired secretion of GIP and normal secretion of GLP-1 after OGTT have been demonstrated in post-menopausal women with IGT [27], which supports our findings. In patients with overt type 2 diabetes, both increased, normal and decreased secretion of GIP and GLP-1 have been reported [28-30]. Although these controversial results may be explained by many different factors (e.g. differences in assays, diabetes duration, ethnicity), the possibility exists that the secretion of incretin hormones is a distinct feature of various type 2 diabetic phenotypes that have emerged from different prediabetic i-IFG or i-IGT states. Obviously, this hypothesis needs to be tested in a prospective setting.

The observed reduced GIP secretion may contribute to the impaired insulin secretion during OGTT in individuals with i-IGT. The extent to which the elevated GLP-1 secretion during OGTT in the i-IFG individuals represents a compensatory mechanism to maintain near normal absolute insulin secretion rates, or whether it represents a primary intrinsic metabolic variant of this distinct prediabetic phenotype is unknown. Previous studies suggested that impaired GLP-1 secretion in overt type 2 diabetes is a secondary phenomenon $[31,32]$. Thus, the possibility remains that compensation for decreased insulin secretion by elevated GLP-1 secretion may occur at the earliest stages of abnormal glucose homeostasis, but that this compensation may be lost again when (postprandial) glucose levels increases.

Insulin resistance Our data clearly show that Europid individuals with i-IGT exhibit insulin resistance in the periphery, whereas those with i-IFG have normal peripheral insulin sensitivity. This is consistent with the findings of previous studies using the clamp technique in both i-IFG $[11,33,34]$ and i-IGT individuals $[1,11,33-35]$.

By use of ${ }^{3} \mathrm{H}$-labelled glucose measurements of glucose turnover rates, we did not detect any evidence of hepatic insulin resistance in either i-IFG or i-IGT individuals. Another study [34] demonstrated hepatic insulin resistance but not an absolute increased EGP in individuals with i-IFG. Differences in BMI, ethnicity and sex distribution as well as different cutoff points for i-IFG (5.6 vs $6.1 \mathrm{mmol} / \mathrm{l}$ ) between our study and the other study may have caused these different findings.

Glucagon The finding of significantly elevated fasting and post-load plasma glucagon levels in prediabetic individuals with i-IFG and i-IGT is novel and potentially important, indicating that abnormal pancreatic alpha cell function is a significant, and maybe primary, player of importance for the abnormal glucose homeostasis at this very early prediabetic time-point. Nevertheless, our findings are consistent with previous studies demonstrating reduced suppression of glucagon during OGTT in individuals with fasting hyperglycaemia [36] and IGT [37, 38].

Interestingly, the increased fasting glucagon secretion was not followed by increased EGP in either i-IFG or i-IGT individuals. In individuals with $\mathrm{i}-\mathrm{IFG}$, this paradox could, however, reflect an autoregulatory effect of even mild hyperglycaemia on EGP [39]. Furthermore, it could also reflect a loss of responsiveness of the liver to glucagon (i.e. hepatic glucagon resistance) [40] in one or both prediabetic groups. In that respect, even in patients with overt type 2 diabetes, EGP is only slightly elevated in the absolute sense because of the suppressive effect of glucose per se on EGP [39].

It has been suggested that in patients with type 2 diabetes, the pancreatic alpha cells are hypo-responsive to the suppressive effects of glucose [41], and it is thus likely that the alpha cells in i-IFG and i-IGT may also be hypo-responsive to 
glucose. Accordingly, we suggest that a glucose-specific defect in the pancreatic alpha cells as well as in the pancreatic beta cells [41] is an early event in the development of type 2 diabetes. Our results thereby indicate that the disproportionately elevated fasting glucagon levels as well as the reduced glucose-induced suppression of glucagon secretion observed in patients with overt type 2 diabetes [42] may represent a primary rather than a secondary defect of the disease.

Study limitations With a combination of a stringent epidemiological approach and detailed state-of-the-art human physiological methods, we have studied the pathophysiology of i-IFG and i-IGT in a well-characterised, homogeneous Europid population. One potential drawback of the study, however, refers to possible sex differences, which have also been reported in other studies [3, 4]. The low number of women with i-IFG made an analysis of sex differences impossible. However, additional statistics performed only on men supported our findings for all variables presented in Table 2, although less significantly because of the lower number of individuals.

At baseline (1999-2001), participants at high risk of cardiovascular disease were offered diet and lifestyle intervention for up to 6 months [12]. In this particular study population, $11 \%$ participated in this intervention. However, since the participation was distributed in all three groups (two with NGT, one with i-IFG, four with i-IGT), we assume that the significance of the intervention on the reported pathophysiological characteristics is negligible.

Implications There is a strong need for studies addressing the question of how individuals with i-IFG and i-IGT progress to diabetes and most importantly how this may be prevented. Insulin-sensitive i-IFG individuals may, in contrast to insulin resistant i-IGT individuals, not necessarily benefit from lifestyle interventions, primarily targeting improvement of peripheral insulin sensitivity. A study of healthy Australian men and women [43], showing that physical activity was associated with reduced $2 \mathrm{~h}$ PG but not FPG, supports this hypothesis. However, more knowledge needs to be obtained from prospective studies. While it is uncertain whether lifestyle interventions prevent diabetes in i-IFG to the same extend as seen in IGT individuals [44], other prevention strategies targeting glucagon and/or GLP-1 secretion or action may turn out to be beneficial in both i-IFG and i-IGT prediabetic individuals.

In conclusion, the present study showed that Europid individuals with early identified i-IFG and i-IGT have the same degree of alpha and beta cell dysfunctions, but only i-IGT individuals exhibit peripheral insulin resistance. During oral glucose ingestion, those with i-IGT exhibit impaired secretion of GIP, possibly contributing to an impairment of insulin secretion, while those with i-IFG have elevated GLP-1 concentrations, potentially maintaining their insulin secretion and glucose tolerance in the normal range after oral glucose ingestion. These results highlights the importance of discriminating between estimates of insulin secretion derived from OGTTs vs IVGTTs as well as the impact of correcting for in vivo insulin action when estimating beta cell function.

Acknowledgements This study was supported by the Danish Ministry of Science, Technology and Innovation, the Danish Diabetes Association, the Novo Nordisk Foundation, the Foundation of Gerda and Aage Haensch and by an EXGENESIS grant (005272) from the European Union. The authors thank T. Jørgensen (principal investigator), H. Ibsen, T. Thomsen and C. Pisinger of the Steering Committee for Inter99, the laboratory technicians and all the participants. The protocol was in accordance with the Helsinki declaration and approved by the local ethical committee.

Duality of interest K. Borch-Johnsen is head of the Steno Diabetes Center, a hospital integrated in the Danish National Healthcare Service, but owned by Novo Nordisk. K. Borch-Johnsen holds shares in Novo Nordisk Inc. The other authors declare that they have no duality of interest associated with this manuscript.

\section{References}

1. Weyer C, Bogardus C, Pratley RE (1999) Metabolic characteristics of individuals with impaired fasting glucose and/or impaired glucose tolerance. Diabetes 48:2197-2203

2. Abdul-Ghani MA, Tripathy D, DeFronzo RA (2006) Contributions of beta-cell dysfunction and insulin resistance to the pathogenesis of impaired glucose tolerance and impaired fasting glucose. Diabetes care 29:1130-1139

3. Tripathy D, Carlsson M, Almgren P et al (2000) Insulin secretion and insulin sensitivity in relation to glucose tolerance: lessons from the Botnia Study. Diabetes 49:975-980

4. Hanefeld M, Koehler C, Fuecker K, Henkel E, Schaper F, TemelkovaKurktschiev T (2003) Insulin secretion and insulin sensitivity pattern is different in isolated impaired glucose tolerance and impaired fasting glucose - the risk factor in impaired glucose tolerance for atherosclerosis and diabetes study. Diabetes Care 26:868-874

5. Davies MJ, Raymond NT, Day JL, Hales CN, Burden AC (2000) Impaired glucose tolerance and fasting hyperglycaemia have different characteristics. Diabet Med 17:433-440

6. Carnevale-Schianca GP, Rossi A, Sainaghi PP, Maduli E, Bartoli E (2003) The significance of impaired fasting glucose versus impaired glucose tolerance: importance of insulin secretion and resistance. Diabetes Care 26:1333-1337

7. Novoa FJ, Boronat M, Saavedra P et al (2005) Differences in cardiovascular risk factors, insulin resistance, and insulin secretion in individuals with normal glucose tolerance and in subjects with impaired glucose regulation: the Telde study. Diabetes Care 28: 2388-2393

8. Piche ME, Despres JP, Pascot A et al (2004) Impaired fasting glucose vs glucose intolerance in pre-menopausal women: distinct metabolic entities and cardiovascular disease risk? Diabet Med 21:730-737

9. Snehalatha C, Ramachandran A, Sivasankari S, Satyavani K, Vijay V (2003) Insulin secretion and action show differences in impaired fasting glucose and in impaired glucose tolerance in Asian Indians. Diabetes Metab Res Rev 19:329-332 
10. Abdul-Ghani MA, Sabbah M, Kher J, Minuchin O, Vardi P, Raz I (2006) Different contributions of insulin resistance and beta-cell dysfunction in overweight Israeli Arabs with IFG and IGT. Diabetes Metab Res Rev 22:126-130

11. Meyer C, Szoke E, Pimenta W et al (2006) Different mechanisms for impaired fasting glucose and impaired postprandial glucose tolerance in humans. Diabetes Care 29:1909-1914

12. Jørgensen T, Borch-Johnsen K, Thomsen TF, Ibsen H, Glumer C, Charlotta P (2003) A randomized non-pharmacological intervention study for prevention of ischaemic heart disease: baseline results Inter99 (1). Eur J Cardiovasc Prevention Rehab 10:377-386

13. World Health Organization (1999) Definition, diagnosis and classification of diabetes mellitus and its complications. Report of a WHO consultation. Part 1: diagnosis and classification of diabetes mellitus. WHO, Geneva, pp 1-59

14. Hother-Nielsen O, Beck-Nielsen H (1990) On the determination of basal glucose production rate in patients with type 2 (noninsulin-dependent) diabetes mellitus using primed-continuous 3$\left[{ }^{3} \mathrm{H}\right]$ glucose infusion. Diabetologia 33:603-610

15. DeFronzo RA, Tobin JD, Andres R (1979) Glucose clamp technique: a method for quantifying insulin secretion and resistance. Am J Physiol 237:E214-E223

16. Storgaard H, Song XM, Jensen $C B$ et al (2001) Insulin signal transduction in skeletal muscle from glucose-intolerant relatives with type 2 diabetes. Diabetes 50:2770-2778

17. Krarup T, Madsbad S, Moody AJ et al (1983) Diminished immunoreactive gastric inhibitory polypeptide response to a meal in newly diagnosed type I (insulin-dependent) diabetics. J Clin Endocrinol Metab 56:1306-1312

18. Ørskov C, Rabenhøj L, Wettergren A, Kofod H, Holst JJ (1994) Tissue and plasma concentrations of amidated and glycineextended glucagon-like peptide I in humans. Diabetes 43:535-539

19. Holst JJ (1982) Evidence that enteroglucagon (II) is identical with the C-terminal sequence (residues 33-69) of glicentin. Biochem J 207:381-388

20. Steele R (1959) Influences of glucose loading and of injected insulin on hepatic glucose output. Ann N Y Acad Sci 82:420-430

21. Seltzer HS, Allen EW, Herron AL, Brennan MT (1967) Insulin secretion in response to glycemic stimulus: relation of delayed initial release to carbohydrate intolerance in mild diabetes mellitus. J Clin Invest 46:323-335

22. Abdul-Ghani MA, Matsuda M, Balas B, DeFronzo RA (2007) Muscle and liver insulin resistance indexes derived from the oral glucose tolerance test. Diabetes Care 30:89-94

23. Festa A, D'Agostino R, Hanley AJ, Karter AJ, Saad MF, Haffner SM (2004) Differences in insulin resistance in nondiabetic subjects with isolated impaired glucose tolerance or isolated impaired fasting glucose. Diabetes 53:1549-1555

24. Osei K, Gaillard T, Schuster DP (1997) Pathogenetic mechanisms of impaired glucose tolerance and type II diabetes in AfricanAmericans. The significance of insulin secretion, insulin sensitivity, and glucose effectiveness. Diabetes Care 20:396-404

25. Pimenta WP, Santos ML, Cruz NS, Aragon FF, Padovani CR, Gerich JE (2002) Brazilian individuals with impaired glucose tolerance are characterized by impaired insulin secretion. Diabetes Metab 28:468-476

26. Mooy JM, Grootenhuis PA, de Vries $\mathrm{H}$ et al (1996) Intraindividual variation of glucose, specific insulin and proinsulin concentrations measured by two oral glucose tolerance tests in a general Caucasian population: the Hoorn Study. Diabetologia 39:298-305

27. Ahrén B, Larsson H, Holst JJ (1997) Reduced gastric inhibitory polypeptide but normal glucagon-like peptide 1 response to oral glucose in postmenopausal women with impaired glucose tolerance. Eur J Endocrinol 137:127-131

28. Elahi D, Aloon-Dyke M, Fukagawa NK et al (1994) The insulinotropic actions of glucose-dependent insulinotropic polypeptide (GIP) and glucagon-like peptide-1 (7-37) in normal and diabetic subjects. Regul Pept 51:63-74

29. Nauck MA, Heimesaat MM, Ørskov C, Holst JJ, Ebert R, Creutzfeldt W (1993) Preserved incretin activity of glucagon-like peptide 1 7-36 amide. but not of synthetic human gastric inhibitory polypeptide in patients with type-2 diabetes mellitus. J Clin Invest 91:301-307

30. Ørskov C, Jeppesen J, Madsbad S, Holst JJ (1991) Proglucagon products in plasma of noninsulin-dependent diabetics and nondiabetic controls in the fasting state and after oral glucose and intravenous arginine. J Clin Invest 87:415-423

31. Vaag AA, Holst JJ, Vølund A, Beck-Nielsen H (2007) Gut incretin hormones in identical twins discordant for non-insulin dependent diabetes mellitus (NIDDM) - evidence for a decreased glucagon-like-peptide 1 secretion during oral glucose ingestion in NIDDM twins. Eur J Endocrinol 135:425-432

32. Knop FK, Vilsboll T, Hojberg PV et al (2007) Reduced incretin effect in type 2 diabetes: cause or consequence of the diabetic state? Diabetes 56:1951-1959

33. Wasada T, Kuroki H, Katsumori $\mathrm{K}$ et al (2004) Who are more insulin resistant, people with IFG or people with IGT? Diabetologia 47:759-760

34. Abdul-Ghani MA, Jenkinson CP, Richardson DK, Tripathy D, DeFronzo RA (2006) Insulin secretion and action in subjects with impaired fasting glucose and impaired glucose tolerance-results from the veterans administration genetic epidemiology study. Diabetes 55:1430-1435

35. Tripathy D, Almgren P, Tuomi T, Groop L (2004) Contribution of insulin-stimulated glucose uptake and basal hepatic insulin sensitivity to surrogate measures of insulin sensitivity. Diabetes Care 27:2204-2210

36. Abdul-Ghani MA, DeFronzo RA (2007) Fasting hyperglycemia impairs glucose - but not insulin-mediated suppression of glucagon secretion. J Clin Endocrinol Metab 92:1778-1784

37. Ahrén B, Larsson H (2001) Impaired glucose tolerance (IGT) is associated with reduced insulin-induced suppression of glucagon concentrations. Diabetologia 44:1998-2003

38. Mitrakou A, Kelley D, Mokan M et al (1992) Role of reduced suppression of glucose production and diminished early insulin release in impaired glucose tolerance. N Engl J Med 326:22-29

39. Brodsky IG (1999) Hormone, cytokine, and nutrient interactions. In: Shills ME, Olson JA, Shike M, Ross AC (eds) Modern nutrition in health and disease. 9th edn. Lippincott Williams \& Wilkins, Baltimore, MD, pp 699-724

40. Felig P, Wahren J, Hendler R (1976) Influence of physiologic hyperglucagonemia on basal and insulin-inhibited splanchnic glucose output in normal man. J Clin Invest 58:761-765

41. Bock G, la Man C, Campioni M et al (2007) Effects of nonglucose nutrients on insulin secretion and action in people with pre-diabetes. Diabetes 56:1113-1119

42. Ward WK, Bolgiano DC, McKnight B et al (1984) Diminished B cell secretory capacity in patients with noninsulin dependent diabetes mellitus. J Clin Invest 74:1318-1328

43. Healy GN, Dunstan DW, Shaw JE, Zimmet PZ, Owen N (2006) Beneficial associations of physical activity with 2-h but not fasting blood glucose in Australian adults. Diabetes Care 29:2598-2604

44. Knowler WC, Barrett-Connor E, Fowler SE et al (2002) Reduction in the incidence of type 2 diabetes with lifestyle intervention or metformin. N Engl J Med 346:393-403 